\title{
Implicações dos estudos brasileiros em psiquiatria e espiritualidade
}

\author{
Implications of Brazilian studies in psychiatry and spirituality
}

\author{
Alexander Moreira-AlmeidA ${ }^{1}$ \\ ¿ Núcleo de Pesquisas em Espiritualidade e Saúde (Nupes), Faculdade de Medicina da Universidade Federal de Juiz de Fora (UFJF), Juiz de Fora, MG, Brasil.
}

Recebido: 19/9/2012 - Aceito: 20/9/2012

Moreira-Almeida A / Rev Psiq Clín. 2012;39(5):181

Embora tenha havido grande aumento nas publicações e interesse na área de espiritualidade e psiquiatria, essas pesquisas e publicações ainda têm se concentrado na América do Norte e Europa, refletindo as realidades daquelas regiões do planeta. Até alguns anos atrás, havia poucos dados e reflexões sobre o contexto brasileiro. No entanto, felizmente, essa situação tem se revertido com um crescente número de estudos brasileiros sobre o tema sendo publicados. Nesse aspecto, a Revista de Psiquiatria Clínica tem se destacado como instrumento de difusão de pesquisas, revisões e mesmo instrumentos de investigação na área de espiritualidade e psiquiatria. Vale destacar alguns achados publicados nos últimos dois anos pela revista que têm implicações diretas para a pesquisa e a prática clínica.

Um levantamento nacional ${ }^{1}$ mostrou o alto nível de religiosidade da população brasileira, indicando que $83 \%$ dos brasileiros consideram religião como muito importante em suas vidas e mais de um terço frequenta um serviço religioso pelo menos uma vez por semana. Outro achado relevante foi o sincretismo do brasileiro, já que $10 \%$ referiram frequentar mais de uma religião. Provavelmente, esse nível de sincretismo seria ainda maior se fossem investigadas outras formas importantes de participação religiosa, como leitura de livros, ouvir músicas e assistir a programas religiosos de TV ou rádio.

A avaliação da religiosidade em estudos na população brasileira tem sido facilitada pela criação ou tradução/validação de escalas em português. Um estudo recente ${ }^{2}$ validou, em uma amostra de pacientes psiquiátricos, a P-Durel, uma escala de amplo uso internacional e de fácil aplicação por conter apenas cinco itens.

O alto nível de religiosidade entre populações clínicas brasileiras foi demonstrado em estudos envolvendo gestantes realizando prénatal $^{3}$ e pacientes ambulatoriais e internados de um hospital geral ${ }^{4}$. Nesses grupos, a religiosidade ou espiritualidade apresentou implicações clínicas, correlacionando-se com maior qualidade de vida e menos sintomas depressivos e ansiosos.

Pacientes psiquiátricos internados têm direito à assistência religiosa, mas há dúvidas relacionadas ao possível impacto dessas intervenções em certos transtornos mentais, bem como sobre a capacidade de julgamento de certos pacientes. Tais questões têm importantes implicações éticas e legais. Uma discussão desses aspectos e uma experiência de assistência religiosa em um hospital psiquiátrico foram realizadas por Braghetta et al. ${ }^{5}$.
Por fim, artigo de outro país dos BRICS, África do Sul, mostra que psiquiatras ligados a uma universidade em Johanesburgo, independentemente de suas posições religiosas ou espirituais, concordam com a necessidade de incorporar, sob certas condições, a espiritualidade na prática e treinamento em psiquiatria ${ }^{6}$.

Em resumo, esses achados refletem o crescimento de interesse e publicações na área no Brasil e em outros países emergentes. Tornase necessário avançar os estudos e discussões sobre as relações da espiritualidade com a saúde mental em nosso meio. Nesse esforço, poderemos identificar em que ponto a nossa realidade se assemelha e o quanto diverge dos achados epidemiológicos e também dos aspectos éticos, culturais e clínicos relacionados à América do Norte e à Europa, fonte da maioria dos estudos atualmente disponíveis. De especial interesse para futuros estudos são os aspectos de treinamento e aplicação clínica do grande corpo de evidências já disponíveis sobre as relações entre espiritualidade e saúde mental.

\section{Referências}

1. Moreira-Almeida A, Pinsky I, Zaleski M, Laranjeira R. Envolvimento religioso e fatores sociodemográficos: resultados de um levantamento nacional no Brasil. Rev Psiq Clín. 2010;37(1):12-5.

2. Taunay TCDE, Gondim FAA, Macedo DS, Moreira-Almeida A, Gurge LA, Andrade LMS, et al. Validação da versão brasileira da escala de religiosidade de Duke (DUREL). Rev Psiq Clín. 2012;39(4):130-5.

3. Silva CS, Ronzani TM, Furtado EF, Aliane PP, Moreira-Almeida A. Relação entre prática religiosa, uso de álcool e transtornos psiquiátricos em gestantes. Rev Psiq Clín. 2010;37(4):152-6.

4. Rocha NS, Fleck MPA. Avaliação de qualidade de vida e importância dada a espiritualidade/religiosidade/crenças pessoais (SRPB) em adultos com e sem problemas crônicos de saúde. Rev Psiq Clín. 2011;38(1):19-23.

5. Braghetta CC, Lucchetti G, Leão FC, Vallada C, Vallada H, Cordeiro Q. Aspectos éticos e legais da assistência religiosa em hospitais psiquiátricos. Rev Psiq Clín. 2011;38(5):189-93.

6. Abr JVR, Poggenpoel M, Myburgh CPH, Szabo CP. Experiência e visão de psiquiatras acadêmicos sobre o papel da espiritualidade na prática e no treinamento de especialistas em psiquiatria na África do Sul. Rev Psiq Clín. 2012;39(4):122-9. 